Research article

\title{
Gene profiling in white blood cells predicts infliximab responsiveness in rheumatoid arthritis
}

\author{
Thierry Lequerré1,2,3,4, Anne-Christine Gauthier-Jauneau1,2,3, Carine Bansard ${ }^{2,3}$, \\ Céline Derambure ${ }^{1,2,3}$, Martine Hiron2,3,4, Olivier Vittecoq ${ }^{1,2,3,4}$, Maryvonne Daveau',3,4, \\ Othmane Mejjad ${ }^{1}$, Alain Daragon ${ }^{1}$, François Tron ${ }^{2,3,4}$, Xavier Le Loët ${ }^{1,2,3,4}$ and Jean- \\ Philippe Salier2,3,4
}

\author{
${ }^{1} \mathrm{CHU}$ de Rouen, Hôpitaux de Rouen, Service de Rhumatologie, Rouen, F-76000, France \\ 2Inserm, U519, Rouen, F-76000, France \\ ${ }^{3}$ Université Rouen, Faculté de Médecine-Pharmacie, Institut Fédératif de Recherche Multidisciplinaire sur les Peptides, Rouen, F-76000, France \\ ${ }^{4}$ Consortium EGERIE, Rouen, Paris, France
}

Corresponding author: Jean-Philippe Salier, Jean-Philippe.Salier@univ-rouen.fr

Received: 28 Mar 2006 Revisions requested: 16 May 2006 Revisions received: 23 May 2006 Accepted: 8 Jul 2006 Published: 3 Jul 2006

Arthritis Research \& Therapy 2006, 8:R105 (doi:10.1186/ar1990)

This article is online at: http://arthritis-research.com/content/8/4/R105

(C) 2006 Lequerré et al.; licensee BioMed Central Ltd.

This is an open access article distributed under the terms of the Creative Commons Attribution License (http://creativecommons.org/licenses/by/2.0), which permits unrestricted use, distribution, and reproduction in any medium, provided the original work is properly cited.

\begin{abstract}
As indicators of responsiveness to a tumour necrosis factor (TNF) $\alpha$ blocking agent (infliximab) are lacking in rheumatoid arthritis, we have used gene profiling in peripheral blood mononuclear cells to predict a good versus poor response to infliximab. Thirty three patients with very active disease (Disease Activity Score $28>5.1$ ) that resisted weekly methotrexate therapy were given infliximab at baseline, weeks 2 and 6 , and every 8th week thereafter. The patients were categorized as responders if a change of Disease Activity Score $28=1.2$ was obtained at 3 months. Mononuclear cell RNAs were collected at baseline and at three months from responders and nonresponders. The baseline RNAs were hybridised to a microarray of 10,000 non-redundant human cDNAs. In 6 responders and 7 non-responders, 41 mRNAs identified by microarray analysis

were expressed as a function of the response to treatment and an unsupervised hierarchical clustering perfectly separated these responders from non-responders. The informativeness of 20 of these 41 transcripts, as measured by qRT-PCR, was reassessed in 20 other patients. The combined levels of these 20 transcripts properly classified 16 out of 20 patients in a leaveone-out procedure, with a sensitivity of $90 \%$ and a specificity of $70 \%$, whereas a set of only 8 transcripts properly classified 18/ 20 patients. Trends for changes in various transcript levels at three months tightly correlated with treatment responsiveness and a down-regulation of specific transcript levels was observed in non-responders only. Our gene profiling obtained by a noninvasive procedure should now be used to predict the likely responders to an infliximab/methotrexate combination.
\end{abstract}

\section{Introduction}

Rheumatoid arthritis (RA) is a chronic, auto-immune and inflammatory polyarthritis that induces joint damage and disability. Tumour necrosis factor (TNF) $\alpha$ plays a key role in the associated pathological events and has been identified as a therapeutic target. In fact, TNF $\alpha$ blocking agents (TBAs), such as infliximab, etanercept, and adalimumab, have revolutionized the therapeutic care of methotrexate-resistent patients. Various clinical trials with a TBA/methotrexate combination have shown efficacy in $60 \%$ to $80 \%$ of such patients [1-3].
TBAs reduce joint inflammation, slow down joint damage and improve physical function [4,5]. Still, $20 \%$ to $40 \%$ of the RA patients given a TBA/methotrexate combination do not respond to this treatment [1-3]. Moreover, TBAs may have side effects and are costly [6] and the efficacy of any given TBA in a given patient is unpredictable $[7,8]$. For these reasons, predicting responsiveness to a given TBA or other emerging biotherapies (such as inhibitors of the interleukin-1 or interleukin-6 pathways) would be most useful. Markers that have proven informative for RA diagnosis or prognosis, such

CRP = C-reactive protein; DAS = disease activity score; DMARD = disease-modifying anti-rheumatic drug; PBMC = peripheral blood mononuclear cell; qRT-PCR = real-time, quantitative reverse transcription PCR; RA = rheumatoid arthritis; $\mathrm{SAM}=$ significance analysis of microarrays; TBA $=\mathrm{TNF} \alpha$ blocking agent; TNF, tumour necrosis factor. 
Table 1

\begin{tabular}{|c|c|c|}
\hline Transcript & Forward & Reverse \\
\hline AKAP9 & 5'-TGTTACTGGGTGGGTTCCAG-3' & 5'-CAGAACCTGTGACTCGATGC-3' \\
\hline COX7AL2 & 5'-TGATTTCCCTGGAGGTTCTG-3' & 5'-CCCCGAGGTGACTAACTCAA-3' \\
\hline ELMOD2 & 5'-AGCTCСTGСТСССССТАGTT-3' & 5'-TCGCTGCAATTCACACTTCC-3' \\
\hline EPS15 & 5'- GTCTTCCTTCCССТСССTTG-3' & 5'-GCAGCATCAGAAGCCAACAC-3' \\
\hline FBOX5 & 5'-CGCTGTAATTCACCTGCAAA -3' & 5'-GTACCAGGCAGGGGACCTAT-3' \\
\hline HLA-DPB1 & 5'-GACCTTCCAGATCCTGGTGA-3' & 5'-СTTTCTTGСTCСTCСTGTGC-3' \\
\hline LAMR1 & 5'- GCAGCAGGAACCCACTTAGG-3' & 5'-AATGGCAACAATTGCACGAG-3' \\
\hline MCP & 5'-AGCAATTTGGAGCGGTAAGC-3' & 5'-GTCCAGGTGCAGGATCACAA-3' \\
\hline MRLP22 & 5'-СTCCACAACTGCCTGGAGAA-3' & 5'-AACTGAGCCAAAGCCTGGTC-3' \\
\hline MTCBP1 & 5'-GGAGAAGGGAGACATGGTGA-3' & 5'-ACGAGGCACGTGTTAGTTCC-3' \\
\hline PFKFB4 & 5'-TGGATCCCAAGTCCTTTGTG-3' & 5'-CGCCTTGGACATCTCTTAGC-3' \\
\hline PSMB9 & 5'-GGTTCTTGATTCCCGAGTGTC-3' & 5'-CAGCCAAAACAAGTGGAGGT-3' \\
\hline PTPN12 & 5'-TCCAGCGGGAGGTATTCACT-3' & 5'-TGGTCCTTTGGGTTTTCCAC-3' \\
\hline QIL1 & 5'-CCTCATCAAGGGAAGTGTGG-3' & 5'-GGAGTCACGGATGGGAAAGT-3' \\
\hline RASGRP3 & 5'-CAGCAAAGGGCAGAAGTCAT-3' & 5'-TAATTGCCGTTGGAGGAGAC-3' \\
\hline RPL35 & 5'-ACCTGAAGGTGGAGCTGTCC-3' & 5'-AGAACACGGGCAATGGATTT-3' \\
\hline RPS16 & 5'-AGTTCTGCTTCTCGGCAGG-3' & 5'-TCTTGGAAGCCTCATCCACA-3' \\
\hline RPS28 & 5'-GACCGGTTCTCAGGGACAGT-3' & 5'-TGACTCCAAAAGGGTGAGCA-3' \\
\hline SCAM1 & 5'-TGTGGCCCAGTACACCTTCA-3' & 5'-CACGTAGCTGGCAGGGAATA-3' \\
\hline TBL2 & 5'-GATGGGGGCTACACCTTCAC-3' & 5'-TGACCCTTCAGGCTCCAGAT-3' \\
\hline $18 S$ & 5'-GTGGAGCGATTTGTCTGGTT-3' & 5'-CGCTGAGCCAGTCAGTGTAG-3' \\
\hline
\end{tabular}

as C-reactive protein (CRP), erythrocyte sedimentation rate, autoantibodies (for example, rheumatoid factors and anticyclic citrullinated peptide antibodies), metalloproteinases and bone proteins cannot predict the responsiveness to TBAs [9].

Because genetic polymorphisms such as HLA-DR haplotypes have been associated with a variable natural course of RA and a heterogeneous response to conventional disease-modifying anti-rheumatic drugs (DMARDs), a few studies have attempted to identify genetic markers for TBA efficacy and they have focused on the promoters of several cytokine genes [10-12]. For example, sequence variation in the $T N F_{\alpha}$ gene promoter has been associated with a variable response to infliximab [11]. However, similar conclusions hold true for etanercept as well [13] and, therefore, such genotypings are useless for selecting the TBA with greatest benefits [14].

Because response to treatment likely depends on polymorphisms at multiple loci [15], genome-wide analysis of gene expression with cDNA arrays has been recently used to identify markers of responsiveness in the peripheral blood mono- nuclear cells (PBMCs). However, the number of such studies is still very limited $[16,17]$ and very few informative genes have been identified [16]. Moreover, in all instances, too few patients per study precluded statistically valid conclusions [17] or a confirmatory analysis in another, independent set of patients [16].

Owing to transcriptome analysis in PBMCs from RA patients, we have now identified a small subset of transcripts whose combined levels allow one to reliably predict the response to a infliximab/methotrexate combination in methotrexate-resistant patients with very active disease.

\section{Materials and methods Patients}

A total of 33 patients, fulfilling the American College of Rheumatology (ACR) criteria for RA [18] and followed in Rouen University Hospital were included in this study. The criteria for patient eligibility were: methotrexate treatment; disease activity score $28($ DAS28) $=5.1$ [19]; and resistance to at least one DMARD (methotrexate included). Exclusion criteria were: evolving infectious disease; age $<18$ years; no contraception; 
Table 2

Demographic and clinical data of rheumatoid arthritis patients at entry of study

\begin{tabular}{lcccc}
\hline Parameter & \multicolumn{2}{c}{ Responders $^{\mathrm{a}}$} & \multicolumn{2}{c}{ Non-responders } \\
\hline & Subset $1^{\mathrm{b}}(n=6)$ & Subset $2(n=10)$ & Subset $1(n=7)$ & Subset $2(n=10)$ \\
\hline Age (years) & $54.1 \pm 13.8^{\mathrm{c}}$ & $55.2 \pm 9.2$ & $56.1 \pm 11.7$ & $58.9 \pm 11.6$ \\
Sex (men/women) & $1 / 5$ & $2 / 8$ & $1 / 6$ & $4 / 6$ \\
RA duration (years) & $11.7 \pm 8.0$ & $11.1 \pm 7.3$ & $12 \pm 10.2$ & $10.5 \pm 5.3$ \\
Methotrexate (mg/week)d & $12.5 \pm 5.5$ & $13 \pm 2.8$ & $15.4 \pm 2.7 \mathrm{e}$ & $11.5 \pm 3.2$ \\
Prednisone (mg/day) & $12.1 \pm 5.6$ & $8.5 \pm 4.2$ & 5 & $8.2 \pm 5.4$ \\
Patients with NSAIDs & 3 & 6 & 5 & 4 \\
Patients with rheumatoid factor & 4 & 8 & 5 & 6 \\
Patients with anti-CCP absg & 3 & 8 & 8
\end{tabular}

aCategorised as indicated in Materials and methods. ${ }^{\mathrm{T}}$ Transcript levels were measured by microarray analysis for subset 1 or qRT-PCR for subset 2. cMean \pm standard deviation. dMaximally tolerated dose in a given patient. eSignificant difference between subsets 1 and 2 within nonresponders $(p<0.05$, Mann and Whitney's non-parametric test). In this table, all other comparisons were non-significant. Anti-CCP abs, anticyclic citrullinated peptide antibodies; NSAID, non-steroidal anti-inflammatory drugs; RA, rheumatoid arthritis.

Table 3

Clinical data at baseline and at 3 months

\begin{tabular}{|c|c|c|c|c|c|c|c|c|}
\hline & \multicolumn{4}{|c|}{ Responders } & \multicolumn{4}{|c|}{ Non-responders } \\
\hline & \multicolumn{2}{|c|}{ Subset 1} & \multicolumn{2}{|c|}{ Subset 2} & \multicolumn{2}{|c|}{ Subset 1} & \multicolumn{2}{|c|}{ Subset 2} \\
\hline & Baseline & 3 months $^{a}$ & Baseline & 3 months $^{a}$ & Baseline & 3 months ${ }^{a}$ & Baseline & 3 months ${ }^{a}$ \\
\hline $\begin{array}{l}\text { Morning stiffness } \\
\text { (minutes) }^{\mathrm{b}}\end{array}$ & $245 \pm 126^{c}$ & $35 \pm 24.5^{c}$ & $210 \pm 81$ & $58 \pm 70.2^{c}$ & $179 \pm 159$ & $66.4 \pm 86^{c}$ & $133 \pm 84$ & $62 \pm 67.6^{c}$ \\
\hline DAS28 b & $6.4 \pm 1.0$ & $4.2 \pm 0.9^{c}$ & $6.2 \pm 0.7$ & $3.8 \pm 0.6^{c}$ & $5.7 \pm 0.8$ & $5.3 \pm 1.0$ & $5.5 \pm 1.0$ & $4.9 \pm 1.0^{c}$ \\
\hline Pain (0-100 mm VAS) & $59.3 \pm 20.3$ & $29.3 \pm 9.3^{c}$ & $62.5 \pm 15.5$ & $31.3 \pm 14.5^{c}$ & $69.3 \pm 13.1$ & $54.1 \pm 22.1$ & $60.9 \pm 11.4$ & $40.6 \pm 18.4$ \\
\hline ESR (mm/hour) & $44 \pm 26.2$ & $27 \pm 20.3^{c}$ & $27.2 \pm 15.7$ & $11.3 \pm 5.2^{\mathrm{c}}$ & $35.7 \pm 25.7$ & $28.3 \pm 15.3$ & $24.1 \pm 11.5$ & $27.8 \pm 19.2$ \\
\hline $\mathrm{CRP}\left(\mathrm{mg} / \mathrm{l}^{\mathrm{b}}\right.$ & $42 \pm 29.8$ & $20 \pm 15.7^{c}$ & $28.6 \pm 19.7$ & $6.2 \pm 6.1^{c}$ & $18.5 \pm 12.7$ & $13 \pm 8.2$ & $15.8 \pm 15.6$ & $11 \pm 7.3$ \\
\hline HAQ score (0-3 scale) & $1.6 \pm 0.4$ & $0.9 \pm 0.5^{c}$ & $1.8 \pm 0.7$ & $1.2 \pm 0.7^{c}$ & $1.6 \pm 0.4$ & $1.2 \pm 0.3$ & $1.5 \pm 0.4$ & $1.5 \pm 0.4$ \\
\hline
\end{tabular}

Values are mean \pm standard deviation. aResponse assessed just before the fourth infliximab/methotrexate infusion. Significant differences between groups are as follows: bdifference between all responders versus non-responders at baseline $(0.03<p<0.05$, Mann and Whitney's test); other comparisons were non-significant ( $p=0.58$ ); c Difference at baseline versus 3 months in this subset ( $p<0.05$, paired Wilcoxon's test). CRP, C-reactive protein; DAS, disease activity score; ESR, erythrocyte sedimentation rate; HAQ, health assessment questionnaire; VAS, visual analogue scale (patient's assessment of pain).

pregnancy; cancer less than 5 years old; cardiac failure (stage III-IV of the New York Heart Association); and infliximab allergy. This protocol (numbered 2003/007) was approved by the ethics committee of Haute-Normandie (France) and all participants signed an informed consent at the time of enrolment. For one month or more before the start of this study every patient was given fixed amounts of a DMARD and nonsteroidal antiinflammatory drug (NSAID) and did not receive any intra-articular steroid injections. During this study, every patient was given the same doses of methotrexate and prednisone as used before, and was treated with infliximab (Remicade ${ }^{\circledR}$, ScheringPlough, Levallois Perret, France) as recommended by the manufacturer and the French Drug Agency AFSSAPS (intravenous $3 \mathrm{mg} / \mathrm{kg}$ infliximab at weeks $0,2,6$, and every 8 th week thereafter). Before each infiximab infusion, DAS28, plasma CRP level, patient's assessment of pain (0 to $100 \mathrm{~mm}$ visual analogue scale), duration of morning stiffness, and physical function scored with the French version of the Health Assessment Questionnaire for RA [20] were recorded. Just before the 4 th infusion (that is, at 3 months), the patients were categorized as responders whenever a change of DAS28 $=1.2$ was obtained. All others were categorized as non-responders.

\section{PBMC isolation and mRNA extraction and labelling}

The PBMCs were isolated from venous blood by FicollHypaque centrifugation and total RNAs were extracted by a standard phenol/chloroform procedure, quality controlled on an Agilent 2100 Bioanalyzer (Agilent Technologies, Palo Alto, 


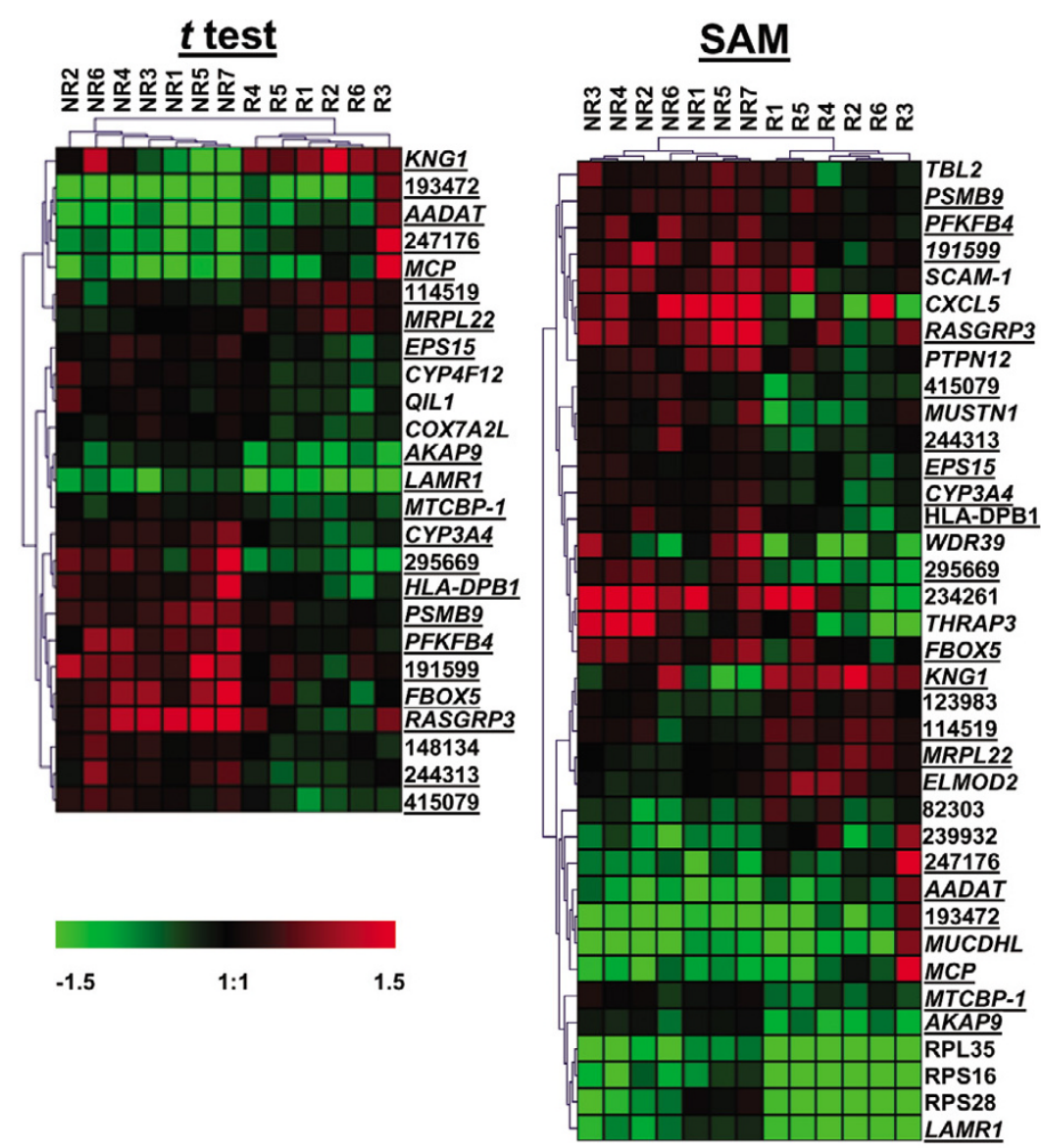

Clustering of rheumatoid arthritis patients as responders versus non-responders. Transcripts in peripheral blood mononuclear cells from six responders (R) or seven non-responders (NR) who were included in two training subsets (subset 1 in text and Tables 2 and 3 ) were studied by microarray analysis. Informative transcripts as selected by a statistical analysis ( $t$ test, 25 transcripts; significance analysis of microarrays (SAM), 37 transcripts) were next used for an unsupervised hierarchical clustering of the same 13 patients, listed as columns. The gene names are listed as rows (expressed sequence tags are noted with a plain, five to six digit IMAGE clone number). The genes are underlined whenever they were selected by both SAM and $t$ test. Transcript levels are expressed as ratios (level in sample/level in internal, arbitrary standard). Scale bar (log2 ratio): decreased (green), increased (red) or identical (black) ratio in sample versus standard (grey squares are missing values).

USA) and frozen at $-80^{\circ} \mathrm{C}$ until further use. An internal, arbitrary standard was made of a mixture of total RNAs from PBMCs taken from three healthy donors. The oligodT-primed poly $(A)$ mRNAs were labelled with $\left[\alpha^{33} P\right] d C T P$ as previously described [21], and the resulting, labelled cDNAs were immediately used for hybridisation.

\section{Transcriptome analysis and qRT-PCR}

Our array covering 12,000 cDNA probes for 10,000 nonredundant genes and various negative controls as well as nylon arraying of PCR-amplified probes and hybridisation of $\left[\alpha^{33} P\right] d C T P-l a b e l l e d$ mRNAs have all been extensively described and validated in a previous report [21]. Briefly, cDNA probes selected on the basis of a tissue-preferred expression in liver corresponded to genes with a liverrestricted expression (10\% of the probes) as well as genes with an hepatic expression along with a broad expression in some (50\%) or many non-hepatic tissues (40\%) [21]. All arrays were made from a single batch of cDNA probes. Every RNA sample was hybridised at least twice on separate arrays. Whenever necessary, the sequence of cDNA probes was controlled with an ABI3100 capillary sequencer (Applied Biosystems APPLERA-France, Courtaboeuf, France). Real-time, quantitative reverse transcription PCR (qRT-PCR) of mRNAs and normalization with the 18S RNA amount were done in duplicate as described [21]. The primers designed with the Primer3 software [22] are listed in Table 1.

\section{Image analysis and data mining}

Image analysis with the XDotsReader software, version 1.8 (COSE, Le Bourget, France), subtractions of noise and spot background, and image normalization with the median value of all signals per image were done exactly as previously detailed [21]. A transcript was considered to be expressed if at least two hybridisations provided a positive signal. The resulting, normalized values were used for a selection of significantly 
Table 4

\begin{tabular}{|c|c|c|c|c|c|}
\hline IMAGE clonea & Encoded protein & Symbolb & Gene localisation & $\mathrm{SAM}^{\mathrm{C}}$ & $t$ test $^{d}$ \\
\hline 295669 & Clone 1OPTELO13 & - & - & -3.77 & 0.001 \\
\hline 77684 & CytP450, family 3 , subfamily A, polypeptide 4 & CYP3A4 & $7 q 21.1$ & -2.90 & $<10^{-4}$ \\
\hline 417137 & A kinase (PRKA) anchor protein 9 & AKAP9 & $7 q 21-q 22$ & -2.83 & 0.002 \\
\hline 415079 & Hypothetical protein DKFZp566M1046 & - & - & -2.78 & 0.001 \\
\hline 1848509 & $\begin{array}{l}\text { RP1 containing part of thyroid hormone receptor- } \\
\text { associated protein } 3\end{array}$ & THRAP3 & $1 p 34.3$ & -2.56 & NS \\
\hline 234261 & RP11-750K11 & - & - & -2.53 & NS \\
\hline 198699 & C-X-C chemokine ligand 5 (ENA78) & CXCL5 & $4 q 12-q 13$ & -2.50 & NS \\
\hline 730048 & Ribosomal protein SA (37LRP) & LAMR1 & $3 p 21.3$ & -2.43 & 0.007 \\
\hline 56923 & F-box protein 5 & FBXO5 & $6 q 25-q 26$ & -2.42 & 0.006 \\
\hline 1524020 & $\begin{array}{l}\text { RAS guanyl releasing protein } 3 \text { (calcium and } \\
\text { DAG-regulated) }\end{array}$ & RASGRP3 & $2 p 25.1-p 24.1$ & -2.41 & 0.004 \\
\hline 756784 & WD repeat domain 39 & WDR39 & $2 q 11.2$ & -2.40 & NS \\
\hline 244313 & Bac clone RP11-576F1 & - & - & -2.39 & 0.002 \\
\hline 124452 & $\begin{array}{l}\text { 6-Phosphofructo-2-kinase/fructose-2,6- } \\
\text { biphosphatase } 4\end{array}$ & PFKFB4 & $3 p 22-p 21$ & -2.33 & 0.003 \\
\hline 724887 & Major HLA, class II, DP beta 1 & HLA-DPB1 & $6 p 21.3$ & -2.32 & $<10^{-4}$ \\
\hline 416493 & Ribosomal protein L35 & RPL35 & $9 q 34.1$ & -2.25 & NS \\
\hline 191599 & Hypothetical protein FU13614 & - & - & -2.23 & 0.006 \\
\hline 726045 & Ribosomal protein S16 & RPS16 & $19 q 13.1$ & -2.24 & NS \\
\hline 772993 & Similar to 40 S ribosomal protein $\mathrm{S} 28$ & RPS28 & $19 \mathrm{p} 13.2$ & -2.23 & NS \\
\hline 110169 & Proteasome subunit $\beta$ type 9 (LMP2) & PSMB9 & $6 p 21.3$ & -2.17 & 0.006 \\
\hline 346678 & Musculoskeletal, embryonic nucleic protein 1 & MUSTN1 & $3 p 21.1$ & -2.16 & NS \\
\hline 741027 & Vinexin $\beta$ (SH3-containing adaptor molecule-1) & SCAM-1 & $8 p 21.3$ & -2.15 & NS \\
\hline 428222 & EGF receptor pathway substrate 15 & EPS15 & $1 \mathrm{p} 32$ & -2.12 & 0.003 \\
\hline 740374 & Transducin (beta)-like 2 & TBL2 & $7 q 11.23$ & -2.12 & Ns \\
\hline 774502 & $\begin{array}{l}\text { Protein tyrosine phosphatase, non-receptor type } \\
12\end{array}$ & PTPN12 & $7 q 11.23$ & -2.09 & NS \\
\hline 320298 & $\begin{array}{l}\text { Membrane-type } 1 \text { matrix metalloprotein } \\
\text { cytoplasmic tail binding protein } 1\end{array}$ & МТСВР-1 & $2 p 25.2$ & -2.04 & 0.005 \\
\hline 148134 & $\mathrm{RP} 1-29 \mathrm{~K} 1$ containing $K i A A 0426$ & - & - & NS & 0.002 \\
\hline 127203 & CytP450, family 4 , subfamily F, polypeptide 12 & CYP4F12 & $19 p 13.1$ & NS & 0.005 \\
\hline 428560 & QIL1 protein & QIL1 & $19 p 13.3$ & NS & 0.009 \\
\hline 810626 & $\begin{array}{l}\text { Cytochrome c oxidase subunit Vlla polypeptide } 2 \\
\text { like }\end{array}$ & COX7A2L & $2 p 21$ & NS & 0.007 \\
\hline 123983 & Clone PR13 & - & - & +1.80 & NS \\
\hline 486624 & ELMO domain containing 2 & ELMOD2 & $4 q 31.21$ & +1.85 & NS \\
\hline 114519 & FLJ 14775 & - & - & +1.90 & 0.007 \\
\hline 357960 & Mitochondrial ribosomal protein L22 & MRPL22 & $5 q 33.1-q 33.3$ & +1.99 & 0.009 \\
\hline 82303 & Hypothetical protein BC009264 & - & - & +2.12 & NS \\
\hline 247517 & Mucin and cadherin-like & MUCDHL & $11 \mathrm{p} 15.5$ & +2.40 & NS \\
\hline 194455 & Membrane cofactor protein (CD46) & MCP & $1 \mathrm{q} 32$ & +2.30 & 0.005 \\
\hline 247176 & RP116103J18 & - & - & +2.41 & $<10^{-4}$ \\
\hline 195723 & Kininogen 1 & KNG1 & $-3 q 27$ & +2.46 & 0.009 \\
\hline
\end{tabular}


Table 4 (Continued)

Transcripts as predictors of infliximab responsiveness

\begin{tabular}{|c|c|c|c|c|c|}
\hline 239932 & ELAC homolog 2 & - & - & +2.46 & NS \\
\hline 244896 & Aminoadipate aminotransferase & AADAT & $4 q 33$ & +2.52 & 0.002 \\
\hline 193472 & RP11-722P15 & - & - & +2.68 & 0.002 \\
\hline
\end{tabular}

alMAGE clone number as a unique identifier. bBold indicates a transcript that was further tested by qRT-PCR. cSignificance analysis of microarrays (SAM) value as an indicator of significant transcript variation in responders versus non-responders. A positive or negative value indicates an over- or underexpression at baseline in responders versus non-responders, respectively. $\mathrm{d} P$ value of a $t$ test as an indicator of significant transcript variation in responders versus non-responders. NS, non- significant.

regulated mRNAs, that is, those with an abundance that differed in two or more comparisons between two samples, using a funnel-shaped confidence interval $(p<0.05)$ calculated from every mRNA detected per hybridisation [21]. This results in a false discovery rate that is below $10 \%$ of the total number of regulated mRNAs. Statistical analyses were done with the R software [23]. The TIGR Multiexperiment viewer (Tmev version 2.2) [24] was used for unsupervised hierarchical clustering $(\mathrm{HC})$ using the average dot product and complete linkage options, the leave-one-out cross-validation, and the supervised statistical tool Significance Analysis of Microarrays (SAM) for identification of discriminant transcripts [25] with a false discovery rate set at $<1 \%$. Information about our clinical and experimental data complies with the recommendations for the minimum information about microarray experiments (MIAME) and the raw data have been deposited (accession number GSE3592) in the GEO repository [26].

\section{Results}

\section{RA patients and response to treatment}

We categorized patients into two groups, responders (R1 to R16) and non-responders (NR1 to NR17) to an infliximab/ methotrexate combination, at three months according to the EULAR criteria, as recommended [18]. Tables 2 and 3 provide demographic and clinical information for these 33 patients, at entry and at 3 months. The average disease duration was 11 to 12 years and the DAS28 score indicated that all these patients had a high level of RA activity, which fits with their resistance to one or more DMARDs. Before treatment, three variables (morning stiffness, DAS28, CRP level) were slightly different in responders compared to non-responders. Following treatment, the DAS28 score significantly improved at 3 months in responders (average decrease 2.3) whereas it remained high in non-responders (average decrease 0.4). Patients in both groups were randomly separated into either a training subset (subset 1) for transcriptome analysis or a validation subset (subset 2) for qRT-PCR. At this stage, we paid attention to retaining a relatively large number of patients in subset 2 of both groups. As noted in Tables 2 and 3, most features did not significantly differ between the paired subsets 1 and 2.

\section{Gene profiling in pre-treatment PBMCs correlates with treatment responsiveness}

Gene profiling in PBMCs was studied in the two training subsets (subset 1) of the responders and non-responders groups (a total of 13 patients). On average, 5,282 $\pm 1,253$ transcripts were detected in PBMCs, with $86 \%$ overlap in transcript identities between responders and non-responders (data not shown). To precisely identify the transcripts that were differentially regulated in responders compared to non-responders, we first selected every transcript whose level in at least one responder was significantly different from the median value in non-responders or vice versa. This was assessed with a funnel-shaped confidence interval (see Materials and methods; $p$ $<0.05$ ) and resulted in 2,239 transcripts with an abnormal level in at least 1 out of these 13 patients. From these 2,239 transcripts, we next selected every transcript whose variation between responders and non-responders was statistically significant according to a $t$ test (25 transcripts) and/or SAM (37 transcripts); these transcripts are listed in Figure 1 (total, 41 transcripts; overlap between $t$ test and SAM selections, 21 transcripts) and detailed in Table 4 . The identity of the corresponding microarray cDNA probes was verified by sequencing. Finally, we performed an unsupervised hierarchical clustering of the 13 patients above (subset 1 ). This was based on the levels of the 25 or 37 transcripts indicated above that, in both instances, resulted in a perfect separation of the responders and non-responders into two major clusters (Figure 1).

We wished to confirm that a combination of the above transcript levels could be used as a predictor of responsiveness. For this purpose, we aimed to measure the levels of the above 41 transcripts by qRT-PCR and compare them between our two validation subsets (subset 2 ) from the responder and nonresponder groups (a total of 20 patients). However, among these 41 transcripts, 12 putative transcripts were identified by only one IMAGE clone without knowledge of the intron/exon structure and, therefore, they were not retained. Moreover, among the 29 remaining transcripts, 9 of them failed to provide reliable data by $\mathrm{qRT}$-PCR, despite repeated attempts with various primers. Eventually, 20 out of our 41 transcripts could be reliably quantified by qRT-PCR. As shown in Figure $2 \mathrm{a}$, an unsupervised hierarchical clustering of the 20 patients in subset 2 from the two groups, as based upon these 20 transcript levels, resulted in two major clusters of responders versus 


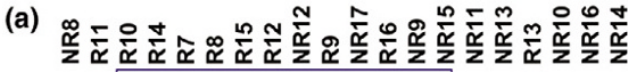

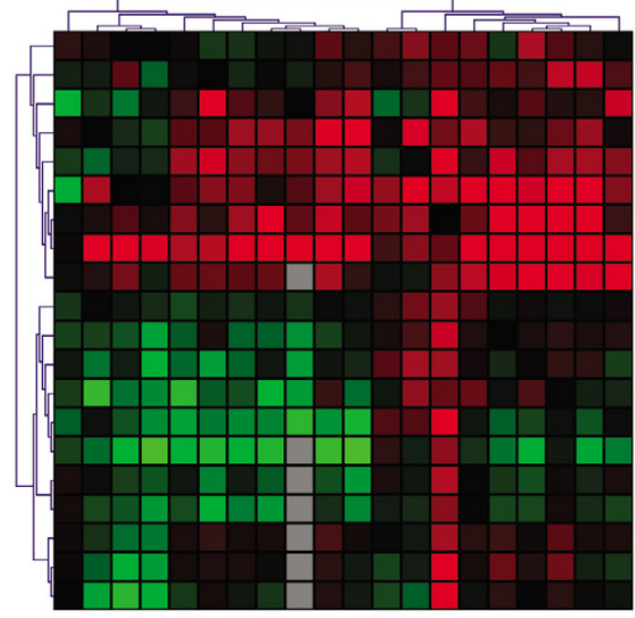

(b)

SCAM1 MTCBP-1 FBOX5 AKAP9 PTNP12 RASGRP 3 PFKFB4 PSMB9 TBL2 QIL-1 MRPL 22 COX7AL2 HLA-DPB1 RPL35 LAMR1 RSP16 RSP28 ELMOD2 $M C P$ EPS15

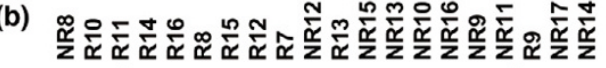
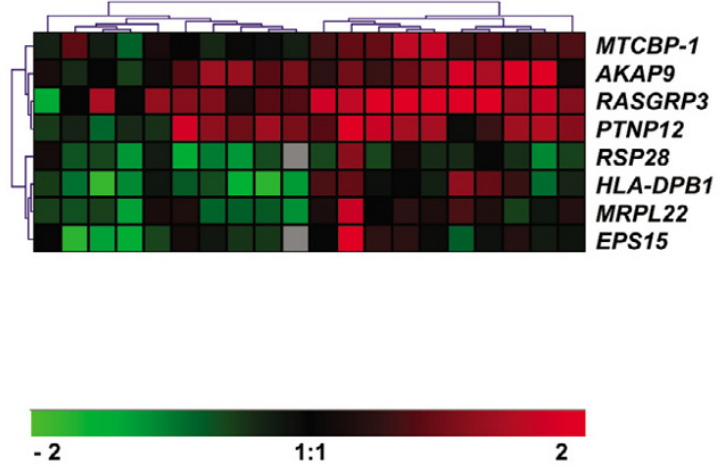

Validation of a narrow selection of transcripts as a tool for clustering responders versus non-responders. Ten responders (R) and ten non-responders (NR) were included in two validation subsets (subset 2 in text and Tables 2 and 3 ). In any given sample of peripheral blood mononuclear cells, the abundances of informative transcripts were determined by qRT-PCR and normalized with the corresponding 18S RNA level. Unsupervised hierarchical clusterings obtained with (a) 20 or (b) 8 selected transcripts are shown. Expression of transcript levels and scale bar are as in Figure 1.

non-responders, with 5 misclassified patients (NR8, NR12, NR17, R13, R16). Despite being informative, such a hierarchical clustering lacks statistical power, and the efficiency of the above set of 20 transcripts for patient classification was thus further evaluated by leave-one-out cross-validation [24]. This procedure identified 4 misclassified patients and indicated that this set of transcripts provides $90 \%$ sensitivity and $70 \%$ specificity for identification of responders and non-responders (Table 5).

To determine the minimal number of transcripts that should be measured for an acceptable prediction of responsiveness, we tested a series of combinations of transcripts in the 20 patients from each subset 2 , and we varied the number and identity of the transcripts actually used (data not shown). With a given set of only 8 transcripts, 16 out of 20 patients could be correctly classified as responders or non-responders by hierarchical clustering (Figure 2b). Finally, leave-one-out cross-validation (Table 5) identified only two misclassified patients and indicated that a given set of 8 transcripts as a predictor of responsiveness was at least as accurate as the set of 20 transcripts above.

\section{Post-treatment transcript levels correlate with treatment responsiveness}

We investigated whether the differences in transcript levels seen in responders compared to non-responders at baseline were also retained at three months. The data obtained by qRTPCR with PBMCs are presented in Figure 3. In responders, 18 out of 20 transcripts (90\%) exhibited a trend towards an increased level at 3 months, although the differences with respect to the levels at baseline were not significant. Strikingly, in non-responders, 19 out of 20 transcripts (95\%) exhibited an opposite trend, that is, a decreased level at 3 months, and this difference was statistically significant for each of 8 transcripts (Figure 3). Overall, the differences in numbers of up- versus down-regulated transcripts in responders versus nonresponders were highly significant, whether considering only the number of transcripts with a significant difference at baseline versus 3 months ( $n=8, p=3.10^{-3}$, Fisher's exact test) or considering the complete set of transcripts and associated trends ( $n=20, p<10^{-4}$ by Fisher's exact test, or $p=0.007$ by analysis of variance). This argues for a regulation of the corresponding genes by one (or more) TNF $\alpha$-dependent pathway(s).

\section{Discussion}

The small set of biological markers usually used for RA diagnosis or prognosis is unable to predict individual responsiveness to TBA [14]. Therefore, to enable such a prediction, global approaches based on proteomics or transcriptomics have been recently considered $[27,28]$. However, in the context of RA, proteomic analysis is still under development [27]. Moreover, very few informative transcripts have been identified by gene profiling [16] and the few studies that used this approach have relied on the differences in transcript levels measured at baseline versus two to three days after treatment onset [17]. This required exposure of every patient to treatment. Furthermore, the narrow time frame of this procedure may blur some significant but late variations with respect to baseline, which eventually limits transcript informativeness. In contrast, we have now measured transcript levels at baseline 
Figure 3

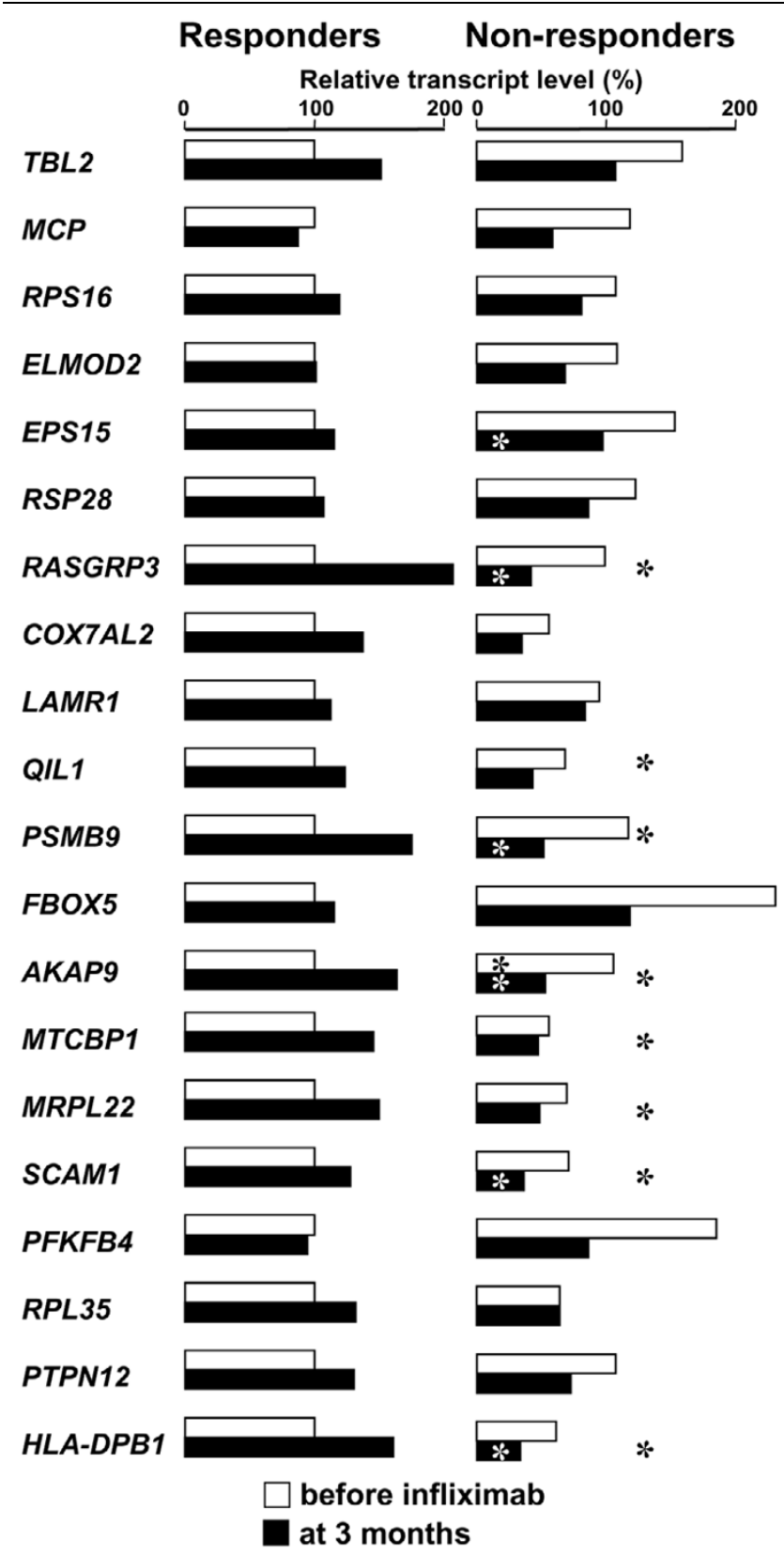

Relative transcript levels at baseline versus three months in responders or non-responders. The patients and transcripts are as in Figure 2a. For every transcript, the 4 levels (median value) shown at baseline and after 3 months in responders and non-responders are expressed as a percentage of the median level at baseline in responders (100\%). Significant differences are all noted in the non-responder panel: asterisk outside closed bar, difference in non-responders at baseline versus three months ( $p<0.05$, paired Wilcoxon's test); asterisk within open bar, difference at baseline in responders versus non-responders $(p<$ 0.05 , Mann and Whitney's test); asterisk within closed bar, difference at 3 months in responders versus non-responders $(p<0.05$, Mann and Whitney's test). In any patient group, a trend towards an increased or decreased level was considered whenever the value at 3 months was, respectively, above or below the value at baseline, whatever the difference of these values. Note that standard deviations are not shown because they are useless for non-parametric statistical tests. as the single predictor of responsiveness. In clinical practice, prediction can then be done without any exposure to treatment, which enables it to be restricted to responders.

Three months of treatment was chosen as the endpoint of our study, as recently recommended by international experts [29], because the objective of an efficient RA treatment is a rapid response. Should this early evaluation at three months disclose a moderate or absent response, this procedure allows another treatment to be used as early as possible. Also, using the DAS28 evolution at three months for classifying our 33 patients as responders or non-responders turned out to be quite reliable in the long run. Indeed, 22 out of 33 patients could be followed for three more years and their infliximab responsiveness, or lack thereof, did not vary over this period, even when increasing infliximab amount and frequency in nonresponders (data not shown).

We aimed to identify a list of transcripts whose combined levels could be related to infliximab/methotrexate responsiveness. In fact, infliximab used alone is known to be efficient only for a short durationbecause the rapid production of anti-infliximab antibodies counteracts the drug's effect, whereas methotrexate advantageously limits this occurrence. The mixture of a cytokine inhibitor (infliximab) and an inhibitor of cell proliferation (methotrexate) is likely to regulate or even co-regulate a complex set of genes; this is a limitation if an understanding of some underlying events in RA is desired.

Gene expression was measured in PBMCs because this is an acknowledged, non-invasive procedure for diagnosis or prognosis of autoimmune diseases [30]. Specifically, in the context of RA, PBMCs as a surrogate tissue are advantageous as they allow for screening in any subject, whereas synovium is amenable to analysis in only a few patients. However, a drawback of such PBMC analysis is the lack of a clear-cut relationship between PBMCs and the affected synovium, which prevents the resulting data from providing an understanding of the RAassociated events in joints. Also, we analysed the PBMC transcriptome with an arbitrary collection of approximately 10,000 cDNA probes [21]. Since this restrictive procedure cannot measure every transcript expressed in the PBMCs, it does not intend to provide a genome-wide view of the RA-associated gene dysregulations in this tissue. Yet, this approach is quite acceptable when inferring prognosis from gene profiling is the major task.

Overall, the present study was not designed primarily to increase our understanding of RA physiopathology but is mostly suited to the predictive use of some combined transcript levels. Our data illustrate that a non-invasive transcriptome analysis done in PBMCs with an array of probes devoid of a specific selection towards the disease under study enables the efficient prediction of treatment responsiveness. Whether these conclusions are solid whatever the microarray/ 
Performance of the number of transcripts for prediction of responsiveness

\begin{tabular}{lcc}
\hline & \multicolumn{2}{c}{ Number of selected transcripts $^{\mathrm{a}}$} \\
\hline & 20 & 8 \\
Number of NR patients classified as NR & 7 & 10 \\
Number of NR patients classified as $\mathrm{R}^{\mathrm{b}}$ & 3 & 0 \\
Number of R patients classified as $\mathrm{R}^{\mathrm{b}}$ & 9 & 8 \\
Number of R patients classified as NR & 1 & 2 \\
Fisher's exact test ${ }^{\mathrm{b}}$ & $p<0.02$ & 0.0007 \\
Sensitivity & $90 \%$ & $80 \%$ \\
Specificity & $70 \%$ & $100 \%$ \\
Positive predictive value & $75 \%$ & $100 \%$ \\
Negative predictive value & $87.5 \%$ & $83 \%$
\end{tabular}

aAs listed in Figure 2a, b. bBy leave-one-out cross-validation with 20 patients, including 10 non-responders (NR) and 10 responders (R) (referred to as validation subset 2 in the text). ${ }^{c} P<0.05$ indicates a significant link between transcript-based classification (R versus NR) and actual responsiveness.

qRT-PCR platforms used, depend on a restricted PBMC subpopulation, or, above all, are useful in the context of an actual therapeutic decision, remains to be tested.

By $t$ test and/or SAM, we identified a short list of 25 to 37 transcripts whose combined expression levels in PBMCs are an efficient discriminator of responders versus non-responders to infliximab/methotrexate. Many of the 25 transcripts identified by $t$ test were no longer significant when using Bonferroni's correction to adjust statistics for the multiple transcripts analysed, but Bonferroni's correction has been recognized as a drastic one when used in this context, which contrasts with the SAM-associated false discovery rate [31]. Moreover, the $t$ test and SAM cross-validated each other for most of the 20 transcripts eventually selected for qRT-PCR as 13 out of 20 $(65 \%)$ such transcripts were significant with both tests (Table 4). Measuring these 20 transcript levels by qRT-PCR indicated that their performance as a predictor of responsiveness was equal to that obtained with 37 transcripts. Ultimately, a given combination of 8 selected transcripts (75\% of them being significant by $t$ test and SAM) as a predictor of responsiveness was as powerful as any higher number of transcripts. This observation that a given combination of very few transcripts can equal or even outperform the predictive strength of a higher number of transcripts has also been reported in another context, namely the response to hepatitis $C$ treatment [32]. This small size for an informative gene set is most encouraging when the need comes for the development of a reliable, fast and cheap assay for measuring informative transcript levels in a clinical setting.

Consistent with the limitations noted above, our list of 29 transcripts did not disclose any significant series of transcripts whose altered levels could point to the physiopathological importance of a predominating function or pathway. Indeed, these transcripts covered such diverse proteins and functions as: ribosomal components (LAMR1, MRPL22, RPL35, RPS16, RPS28), which may suggest the existence of a TNF $\alpha$ dependent pathway in the control of translation; cell adhesion and inhibition of cell migration/invasion (LAMR1, MUCDHL, MTCPB1); cytochromes (CYP3A4, CYP4F12) and cytochrome oxidase (COX7A2L); proteasome-mediated proteolysis (FBXO5, PSMB9); various enzymes (AADAT, PFKFB4); intra- or extracellular signalling (AKAP9, CXCL5, PTPN12, RASGRP3, TBL2, THRAP3), including regulators of the ERK pathway (EPS15, SCAM-1); and innate or adaptive immunity (KNG1, MCP, PSMB9, HLA-DPB1). Two transcripts, namely MUSTN1 and HLA-DPB1, are noteworthy; the MUSTN1 transcript codes for a protein involved in bone development and regeneration [33] and some alleles of the $H L A-D P B 1$ gene have been associated with a relatively high risk of RA occurrence [34].

The opposite variations in transcript levels seen in responders compared to non-responders at three months strongly suggest that the informative transcripts retained in our study originated from TNF $\alpha$-regulated genes. In fact, TNF $\alpha$-dependent expression of the CXCL5, CYP3A4, LAMR1, MCP, and $P S M B 9$ genes, as noted here, has been previously described [35-40]. However, only two of our transcripts, namely MCP and PTPN12, are found among lists of genes that are directly regulated by the TNF $\alpha / N F \kappa B$ pathway, whether in RA [41] or in another context $[42,43]$. Therefore, it is likely that most of our transcripts are indirect TNF $\alpha$ targets. This view fits with the fact that the opposite variations in responders versus nonresponders were observed weeks after the start of TBA. The reason why the transcript levels exhibited a limited trend to upregulation at three months in responders along with a predominating repression in non-responders (Figure 3 ) also fits with indirect TNF $\alpha$ target genes, whose regulation would depend 
on one or more TNF $\alpha$-dependent transcriptional repressor(s). The difference in responders versus non-responders could then result from genetic polymorphisms in binding sites for such repressors.

This situation of variations in binding of transcription factors has been previously described in RA $[11,44]$. Notably, the $308 \mathrm{G} / \mathrm{G}$ genotype of the $T N F \alpha$ gene promoter is known to be associated with a better response to infliximab compared to the $-308 \mathrm{~A} / \mathrm{G}$ or A/A genotype [11]. Other binding sites for repressor(s) could be located in any gene that belongs to the pathway from TNF $\alpha$ signalling to its indirect target genes whose transcripts were found here. If so, identifying such binding site polymorphisms that could predict the extent of responsiveness to TBA deserves further studies. Beyond this, it might well be worth combining the HLA-DRB1 genotype, itself a predictor of responsiveness to methotrexate/sulphasalazine/ hydroxychloroquine in RA [45], with our measure of informative transcript levels, as this might enhance the predictive power of such indicators.

\section{Conclusion}

The combined levels of a small set of discriminative transcripts have provided for the first time a tool for the prediction of infliximab/methotrexate efficacy in patients with long standing (11 to 12 years) and very active RA. It remains to be seen whether our predictive approach can prove useful in patients with recent and/or moderate RA activity or in non-responders given a higher dose of infliximab $(>3 \mathrm{mg} / \mathrm{kg}$ ). Other future studies should identify further gene profiles whose changes correlate with a responsiveness to other TBAs or treatments, such as interleukin-1 receptor antagonists [46]. Ultimately, we anticipate that a small series of parallel tests for such drugspecific combinations of transcripts, as quantified on a specifically designed DNA chip, should allow one to select the most appropriate treatment for every RA patient, with the resulting and beneficial eradication of the non-responder or moderate responder phenotypes.

\section{Competing interests}

A patent application EP 06290789.4 for the set of 20 or 8 transcripts with predictive power (Figure 2) has been deposited by Inserm. The authors declare that they have no competing interests.

\section{Authors' contributions}

TL, XLL and JPS were responsible for designing the study and writing the manuscript. OV, OM, AD, and XLL were responsible for clinical coordination, access to samples, RA evaluation and manuscript improvements. ACGJ, CB, CD, and $\mathrm{MH}$ were responsible for microarrays, qRT-PCRs and data analysis. MD and FT provided numerous manuscript improvements.

\section{Acknowledgements}

$\mathrm{CB}$ is the recipient of a fellowship from the French Ministry for Research. This work was supported in part by a grant from Conseil Régional de Haute-Normandie (France).

\section{References}

1. Bathon JM, Martin RW, Fleischmann RM, Tesser JR, Schiff MH, Keystone EC, Genovese MC, Wasko MC, Moreland LW, Weaver $\mathrm{AL}$, et al.: A comparison of etanercept and methotrexate in patients with early rheumatoid arthritis. N Engl J Med 2000, 343:1586-1593.

2. Keystone EC, Kavanaugh AF, Sharp JT, Tannenbaum H, Hua Y, Teoh LS, Fischkoff SA, Chartash EK: Radiographic, clinical, and functional outcomes of treatment with adalimumab (a human anti-tumour necrosis factor monoclonal antibody) in patients with active rheumatoid arthritis receiving concomitant methotrexate therapy: a randomized, placebo-controlled, 52-week trial. Arthritis Rheum 2004, 50:1400-1411.

3. Maini RN, Breedveld FC, Kalden JR, Smolen JS, Furst D, Weisman MH, St Clair EW, Keenan GF, van der Heijde D, Marsters PA, Lipsky PE: Anti-tumour necrosis factor trial in rheumatoid arthritis with concomitant therapy study group. Sustained improvement over two years in physical function, structural damage, and signs and symptoms among patients with rheumatoid arthritis treated with infliximab and methotrexate. Arthritis Rheum 2004, 50:1051-1065.

4. Klareskog L, van der Heijde D, de Jager JP, Gough A, Kalden J, Malaise M, Martin Mola E, Pavelka K, Sany J, Settas L, et al.: Therapeutic effect of the combination of etanercept and methotrexate compared with each treatment alone in patients with rheumatoid arthritis: double-blind randomised controlled trial. Lancet 2004, 363:675-681.

5. Smolen JS, Han C, Bala M, Maini RN, Kalden JR, van der Heijde D, Breedveld FC, Furst DE, Lipsky PE, ATTRACT Study Group: Evidence of radiographic benefit of treatment with infliximab plus methotrexate in rheumatoid arthritis patients who had no clinical improvement: a detailed subanalysis of data from the antitumour necrosis factor trial in rheumatoid arthritis with concomitant therapy study. Arthritis Rheum 2005, 52:1020-1030.

6. den Broeder A, van de Putte L, Rau R, Schattenkirchner M, Van Riel P, Sander O, Binder C, Fenner H, Bankmann Y, Velagapudi R, et al:: A single dose, placebo controlled study of the fully human anti-tumour necrosis factor-alpha antibody adalimumab (D2E7) in patients with rheumatoid arthritis. J Rheumatol 2002, 29:2288-2298.

7. Ang HT, Helfgott S: Do the clinical responses and complications following etanercept or infliximab therapy predict similar outcomes with the other tumour necrosis factor-alpha antagonists in patients with rheumatoid arthritis? J Rheumatol 2003, 30:2315-2318.

8. Haraoui B, Keystone EC, Thorne JC, Pope JE, Chen I, Asare CG, Leff JA: Clinical outcomes of patients with rheumatoid arthritis after switching from infliximab to etanercept. J Rheumatol 2004, 31:2356-2359.

9. Lequerré T, Jouen F, Brazier M, Clayssens $S$, Klemmer N, Ménard J-F, Mejjad O, Daragon A, Tron F, Le Loët X, Vittecoq O: Autoantibodies, metalloproteinases and bone markers in rheumatoid arthritis patients are unable to predict their responses to infliximab. Rheumatology 2006 in press.

10. Kang CP, Lee KW, Yoo DH, Kang C, Bae SC: The influence of a polymorphism at position -857 of the tumour necrosis factor alpha gene on clinical response to etanercept therapy in rheumatoid arthritis. Rheumatology 2005, 44:547-552.

11. Mugnier B, Balandraud N, Darque A, Roudier C, Roudier J, Reviron D: Polymorphism at position -308 of the tumour necrosis factor alpha gene influences outcome of infliximab therapy in rheumatoid arthritis. Arthritis Rheum 2003, 48:1849-1852.

12. Cuchacovich M, Ferreira L, Aliste M, Soto L, Cuenca J, Cruzat A, Gatica $\mathrm{H}$, Schiattino I, Perez C, Aguirre A, et al.: Tumour necrosis factor-alpha (TNF-alpha) levels and influence of -308 TNFalpha promoter polymorphism on the responsiveness to infliximab in patients with rheumatoid arthritis. Scand J Rheumatol 2004, 33:228-232. 
13. Mugnier B, Roudier J: Factors predicting responsiveness to anti-TNF $\alpha$ therapy in patients with rheumatoid arthritis: using biotherapies rationally. Joint Bone Spine 2004, 71:91-94.

14. Lequerré $T$, Vittecoq $O$, Le Loët $X$ : Comment about the editorial by Bénédicte Mugnier and Jean Roudier entitled "Factors predicting responsiveness to anti-TNF $\alpha$ therapy in patients with rheumatoid arthritis: using biotherapies rationally". Joint Bone Spine 2005, 72:346-347.

15. Bridges SL Jr: Genetic markers of treatment response in rheumatoid arthritis. Arthritis Rheum 2004, 50:1019-1022.

16. Kekow J, Koczan D, Drynda S, Drynda A, Guthke R, Thiesen HJ: Early identification of responders to anti-TNF $\alpha$ therapy by microarrays technique [abstract]. Arthritis Rheum 2004:117.

17. Meisel C, Newton JL, Harney SM, Wordsworth BP, Brown MA: Gene expression profiling of treatment response to anti-TNFalpha therapy in rheumatoid arthritis [abstract]. Arthritis Rheum 2004:120.

18. Arnett FC, Edworthy SM, Bloch DA, McShane DJ, Fries JF, Cooper NS, Healey LA, Kaplan SR, Liang MH, Luthra HS, et al.: The American Rheumatism Association 1987 revised criteria for the classification of rheumatoid arthritis. Arthritis Rheum 1988, 31:315-324.

19. van Gestel AM, Prevoo MLL, van't Hof MA, van Rijswijk MH, van de Putte LB, van Riel PL: Development and validation of the European League Against Rheumatism response criteria for rheumatoid arthritis. Comparison with the preliminary American College of Rheumatology and the World Health Organization/ International League Against Rheumatism criteria. Arthritis Rheum 1996, 39:34-40.

20. Guillemin F, Braincon S, Pourel J: Measurement of the functional capacity in rheumatoid polyarthritis: a French adaptation of the Health Assessment Questionnaire (HAQ). Rev Rhum Mal Osteoartic 1991, 58:459-465.

21. Coulouarn $C$, Lefebvre G, Derambure $C$, Lequerré $T$, Scotte $M$, François A, Cellier D, Daveau M, Salier JP: Altered gene expression in acute systemic inflammation detected by complete coverage of the human liver transcriptome. Hepatology 2004, 39:353-364.

22. Primer 3 [http://frodo.wi.mit.edu]

23. The R Project for Statistical Computing [http://www.rproject.org/]

24. TM4 Microarray Software Suite [http://www.tm4.org]

25. Tusher VG, R Tibshirani, Chu G: Significance analysis of microarrays applied to the ionizing radiation response. Proc Nat Acad Sci USA 2001, 98:5116-5121.

26. Gene Expression Omnibus [http://www.ncbi.nlm.nih.gov/ projects/geo]

27. Drynda S, Ringel B, Kekow M, Kuhne C, Drynda A, Glocker MO, Thiesen HJ, Kekow J: Proteome analysis reveals disease-associated marker proteins to differentiate RA patients from other inflammatory joint diseases with the potential to monitor antiTNFalpha therapy. Pathol Res Pract 2004, 200:165-171.

28. Jarvis JN, Centola M: Gene-expression profiling: time for clinical application? Lancet 2005, 365:199-200.

29. Furst DE, Breedveld FC, Kalden JR, Smolen JS, Burmester GR, Bijlsma JW, Dougados M, Emery P, Keystone EC, Klareskog L, Mease PJ: Updated consensus statement on biological agents, specifically tumour necrosis factor \{alpha\} (TNF\{alpha\}) blocking agents and interleukin-1 receptor antagonist (IL-1 ra), for the treatment of rheumatic diseases. Ann Rheum Dis 2005, 64(Suppl 4):iv2-14.

30. Olsen NJ, Moore JH, Aune TM: Gene expression signatures for autoimmune disease in peripheral blood mononuclear cells. Arthritis Res Ther 2004, 6:120-128.

31. Allison DB, Cui X, Page GP, Sabripour M: Microarray data analysis: from disarray to consolidation and consensus. Nat Rev Genet 2006, 7:55-65

32. Chen L, Borozan I, Feld J, Sun J, Tannis LL, Coltescu C, Heathcote J, Edwards AM, McGilvray ID: Hepatic gene expression discriminates responders and nonresponders in treatment of chronic hepatitis C viral infection. Gastroenterology 2005, 128:1437-1444.

33. Lombardo F, Komatsu D, Hadjiargyrou M: Molecular cloning and characterization of Mustang, a novel nuclear protein expressed during skeletal development and regeneration. FASEB J 2004, 18:52-61.
34. Gao X, Fernandez-Vina M, Olsen NJ, Pincus T, Stastny P: HLADPB1 ${ }^{*} 0301$ is a major risk factor for rheumatoid factor-negative adult rheumatoid arthritis. Arthritis Rheum 1991, 34:1310-1312.

35. Koch AE, Kunkel SL, Harlow LA, Mazarakis DD, Haines GK Burdick MD, Pope RM, Walz A, Strieter RM: Epithelial neutrophil activating peptide-78: a novel chemotactic cytokine for neutrophils in arthritis. J Clin Invest 1994, 94:1012-1018.

36. Persson T, Monsef N, Andersson P, Bjartell A, Malm J, Calafat J, Egesten A: Expression of the neutrophil-activating CXC chemokine ENA-78/CXCL5 by human eosinophils. Clin Exp Allergy 2003, 33:531-537.

37. Chun YJ, Lee S, Yang SA, Park S, Kim MY: Modulation of CYP3A4 expression by ceramide in human colon carcinoma HT-29 cells. Biochem Biophys Res Commun 2002, 298:687-692.

38. Clausse N, van den Brule F, Delvenne P, Jacobs N, FranzenDetrooz E, Jackers $P$, Castronovo V: TNF-alpha and IFN-gamma down-regulate the expression of the metastasis-associated bi-functional $37 \mathrm{LRP} / \mathrm{p} 40$ gene and protein in transformed keratinocytes. Biochem Biophys Res Commun 1998, 251:564-569.

39. Hyc A, Osiecka-Iwan A, Strzelczyk P, Moskalewski S: Effect of IL1 beta, TNF-alpha and IL-4 on complement regulatory protein mRNA expression in human articular chondrocytes. Int $J \mathrm{Mol}$ Med 2003, 11:91-94

40. Groettrup M, van den Broek M, Schwarz K, Macagno A, Khan S, de Giuli R, Schmidtke G: Structural plasticity of the proteasome and its function in antigen processing. Crit Rev Immuno/ 2001 21:339-358.

41. Taberner M, Scott KF, Weininger L, Mackay CR, Rolph MS: Overlapping gene expression profiles in rheumatoid fibroblast-like synoviocytes induced by the proinflammatory cytokines interleukin-1 beta and tumour necrosis factor. Inflamm Res 2005, 54:10-16.

42. Zhou A, Scoggin S, Gaynor RB, Williams NS: Identification of NF-kappa B-regulated genes induced by TNFalpha utilizing expression profiling and RNA interference. Oncogene 2003, 22:2054-2064.

43. Tian B, Nowak DE, Jamaluddin M, Wang S, Brasier AR: Identification of direct genomic targets downstream of the nuclear factor-kappaB transcription factor mediating tumour necrosis factor signaling. J Biol Chem 2005, 280:17435-17448.

44. Schotte $H$, Schluter B, Drynda S, Willeke P, Tidow N, Assmann G, Domschke W, Kekow J, Gaubitz M: Interleukin 10 promoter microsatellite polymorphisms are associated with response to long term treatment with etanercept in patients with rheumatoid arthritis. Ann Rheum Dis 2005, 64:575-581.

45. O'Dell JR, Nepom BS, Haire C, Gersuk VH, Gaur L, Moore GF, Drymalski W, Palmer W, Eckhoff PJ, Klassen LW, et al:: HLADRB1 typing in rheumatoid arthritis: predicting response to specific treatments. Ann Rheum Dis 1998, 57:209-213.

46. Nuki G, Bresnihan B, Bear MB, McCabe D, European Group Of Clinical Investigators: Long-term safety and maintenance of clinical improvement following treatment with anakinra (recombinant human interleukin-1 receptor antagonist) in patients with rheumatoid arthritis : extension phase of a randomized, double-blind, placebo-controlled trial. Arthritis Rheum 2002, 46:2838-2846. 